\title{
Supply chain management curriculum integration in pre-service training in Tanzania
}

\author{
Matiko Machagge*, Dorothy Matoyo, Irene Alenga \\ From The 2nd People that Deliver (2nd PtD) Global Conference on Human Resources in Supply Chain \\ Management \\ Copenhagen, Denmark. 29-30 October 2014
}

\section{Background}

An assessment in 2011 identified the need to incorporate supply chain management (SCM) in academic curricula for health care workers in Tanzania. As a result, a competency-based curricula was developed for pharmacists, pharmacy technicians, clinical officers and nursing cadres. An initiative to train pharmacy graduates in SCM as part of their professional training was thereafter embarked on in 2013 .

\section{Method}

Consultative meetings with various government and health education related institutions resulted in great enthusiasm and built momentum for creation of a pre-service training (PST) curriculum; an effective way of introducing principles and practices of health commodities SCM. Pilot orientation training was provided to 19 lecturers to teach health institutions how and where SCM can be integrated in PST. The acquired skillset enabled them to start teaching SCM in the coming semesters.

\section{Results}

SCM was successfully integrated in the Bachelor of Pharmacy curriculum at the Muhimbili University College of Health Sciences (MUHAS) and the Institute of Health and Allied Sciences (IHAS). A total of 40 pharmacists and 35 pharmaceutical technicians completed training in SCM in 2013. An increasing interest in other public and private training institutions has been realized and currently SCMS is collaborating with St. Luke Foundation at the Kilimanjaro Christian Medical Centres School of Pharmacy and St. John University in Dodoma to integrate SCM in their Diploma of Pharmaceutical Technician's course and Bachelor of Pharmacy course.

\section{Discussion}

Education has been referred to as an effective "social vaccine" to curb the spread and ensure effective management of HIV/AIDS and other major diseases like Malaria and Tuberculosis. Having a knowledgeable human resource pool is paramount to obtaining accurate and timely logistics data to ensure health commodity security, effective and sustainable supply chains in Tanzania. The successful integration of PST is just one step in assuring future commodity security in Tanzania. A monitoring framework focusing on direct performance of pre- versus in -service training is necessary to fully realize the impact of the intervention.

\section{Lessons learned}

Multidisciplinary involvement of government institutions is necessary in ensuring changes in curricula are accepted by all stakeholders and follow government policies and procedures. For this project to have a larger impact the right strategies, policies and plans must be in place for the recruitment and retention of SC workforce and professionalization of SCM.

Published: 17 December 2014

doi:10.1186/2052-3211-7-S1-P14

Cite this article as: Machagge et al:: Supply chain management curriculum integration in pre-service training in Tanzania. Journal of Pharmaceutical Policy and Practice 2014 7(Suppl 1):P14.

* Correspondence: mmachagge@tz.pfscm.org

SCMS \& USAID|DELIVER PROJECT, John Snow Inc. (JSI), Dodoma, Tanzania

(c) 2014 Machagge et al; licensee BioMed Central Ltd. This is an Open Access article distributed under the terms of the Creative Commons Attribution License (http://creativecommons.org/licenses/by/4.0), which permits unrestricted use, distribution, and reproduction in any medium, provided the original work is properly cited. The Creative Commons Public Domain Dedication waiver (http://creativecommons.org/publicdomain/zero/1.0/) applies to the data made available in this article, unless otherwise stated. 